\title{
PEMBERANTASAN DARURAT PENDIDIKAN MELALUI PENINGKATAN SUPERVISI PENDIDIKAN
}

\author{
Nyak Mutya Aulina Khairul Fajri \\ mutyaaulina8@gmail.com
}

\begin{abstract}
ABSTRAK
Maraknya permasalahan yang timbul dalam dunia pendidikan seperti penyimpangan sosial, moral hingga mutu pendidikan itu sendiri menyebabkan Indonesia berada dalam kategori darurat pendidikan yang artinya pendidikan di Indonesia dalam keadaan yang tidak baikbaik saja. Pendidikan merupakan proses mencetak generasi penerus bangsa yang berkualitas. Indonesia adalah salah satu negara berkembang di dunia yang masih mempunyai masalah besar dalam dunia pendidikan. Kita mempunyai tujuan negara yaitu "mencerdaskan kehidupan bangsa" yang seharusnya jadi sumbu perkembangan pembangunan kesejahteraan dan kebudayaan bangsa.
\end{abstract}

Hal yang dirasakan sekarang adalah adanya ketertinggalan didalam mutu pendidikan. Rendahnya mutu pendidikan menghambat penyediaan sumber daya manusia yang mempunyai keahlian dan keterampilan untuk memenuhi pembangunan bangsa di berbagai bidang.

Pada saat ini pendidikan bukan lagi dianggap sebagai suatu hal yang penting, banyak sekali kasus di Indonesia yang mengotori dunia pendidikan. Salah satunya seperti buku pelajaran yang mengandung SARA, buku cerita bergambar yang tidak layak dibaca oleh anak-anak, kurangnya fasilitas yang mendukung saat proses pembelajaran pun menjadi faktor utama dalam dunia pendidikan ini.

Hal tersebut sering kali terjadi khusunya di daerah-daerah terpencil maupun daerah perbatasan di wilayah Indonesia. Daerah terpencil sering kali tidak menjadi sorotan perhatian pemerintah, sedangkan pada kota-kota besar sangat tercukupi akan kebutuhan fasilitasnya, hal inilah yang dapat memicu adanya kesenjangan dan permusuhan antar warga negara Indonesia.

Kata Kunci: Indonesia Darurat Pendidikan, Solusi Darurat Pendidikan.

\section{LATAR BELAKANG}

Pendidikan adalah tonggak kemajuan bangsa. Menjadi bangsa yang maju tentu merupakan cita-cita yang selalu ingin di capai oleh setiap negara di dunia. Sudah menjadi suatu rahasia umum bahwa maju tidaknya suatu negara di pengaruhi oleh faktor pendidikan (Kusumawardhani, 2018).

Pendidikan merupakan proses mencetak generasi penerus bangsa yang berkualitas. Indonesia adalah salah satu negara berkembang di dunia yang masih mempunyai masalah besar dalam dunia pendidikan. Kita mempunyai tujuan negara yaitu "mencerdaskan kehidupan bangsa" yang seharusnya jadi sumbu 
perkembangan pembangunan kesejahteraan dan kebudayaan bangsa (Kusumawardhani, 2018).

Hal yang dirasakan sekarang adalah adanya ketertinggalan didalam mutu pendidikan. Rendahnya mutu pendidikan menghambat penyediaan sumber daya manusia yang mempunyai keahlian dan keterampilan untuk memenuhi pembangunan bangsa di berbagai bidang (Kusumawardhani, 2018).

Di ambang Revolusi Industri 4.0, Indonesia masih memiliki masalah dalam mengelola sumber daya manusia. Ketika persaingan global menuntut orang untuk memiliki kecakapan pengelolaan teknologi tinggi, berdasarkan data SMSG wajah pendidikan Indonesia masih dihantui dengan fakta bahwa ada 13 juta anak tidak mengenyam pendidikan dan 187 ribu anak putus sekolah (Harususilo, 2019).

Masalah keterbatasan pendidikan umumnya berakar dari kemiskinan dan merupakan masalah sangat rumit karena terkait dengan masalah besar lain seperti kurangnya akses asupan makanan bergizi, kurangnya akses terhadap informasi, dan masalah besar lainnya (Harususilo, 2019).

Banyak faktor dan masalah yang menyebabkan pendidikan di Indonesia tidak bisa berkembang, diantaranya: mahalnya biaya pendidikan; fasilitas pendidikan yang kurang memadai; dan, rendahnya kesempatan pemerataan pendidikan (Kusumawardhani, 2018).

Namun pada saat ini pendidikan bukan lagi dianggap sebagai suatu hal yang penting, banyak sekali kasus di Indonesia yang mengotori dunia pendidikan. Salah satunya seperti buku pelajaran yang mengandung SARA, buku cerita bergambar yang tidak layak dibaca oleh anak-anak, kurangnya fasilitas yang mendukung saat proses pembelajaran pun menjadi factor utama dalam dunia pendidikan ini.

Hal tersebut sering kali terjadi khusunya di daerah-daerah terpencil maupun daerah perbatasan di wilayah Indonesia. Daerah terpencil sering kali tidak menjadi sorotan perhatian pemerintah, sedangkan pada kota-kota besar sangat tercukupi akan kebutuhan fasilitasnya, hal inilah yang dapat memicu adanya kesenjangan dan permusuhan antar warga negara Indonesia.

Berdasarkan Undang-undang Nomor 20 Tahun 2003 tentang Sistem Pendidikan Nasional, Peraturan Menteri Pendidikan Nasional No. 12 Tahun 2007 tentang Standar Pengawas Sekolah/Madrasah, dan Peraturan Menteri Pendayagunaan Aparatur Negara dan Refornasi Birokrasi Nomor 21 Tahun 2010 tentang Jabatan Fungsional Pengawas dan Angka Kreditnya, pengawasan pendidikan harus direncanakan, diorganisasikan, dan dilaksanakan selaras dengan paradigma baru pendidikan yang bertumpu pada empat pilar yakni pendidikan untuk semua, pendidikan demokratis, pendidikan yang bertumpu pada kebudayaan lokal, dan pendidikan yang seimbang antara imtaq dan iptek melalui supervisi pendidikan (Nadlir, 2018).

Sebagai kegiatan pengawasan yang mengacu pada unsur pembinaan, supervisi pendidikan yang ada saat ini belum sesuai harapan. Meski terbuti tetap dilakukan hingga saat ini, namun 
hasil dari supervisi pendidikan yang ada justru tidak memperoleh informasi dan data yang sebenarnya (Keswara, 2013).

Hal ini diungkapkan oleh Perwakilan Lembaga Penjamin Mutu Pendidikan (LPMP) DIY Susi Anto MPd dalam kuliah perdana Program Studi S2 Manajemen Pendidikan (MP) Universitas Ahmad Dahlan (UAD). Menurut Susi, supervisi merupakan kegiatan bersifat manusiawi yang dilakukan oleh atasan atau pimpinan terhadap berbagai aktivitas yang ada dibawahnya (Keswara, 2013).

Supervisi dilakukan agar kondisi pekerjaan yang sedang dilakukan dapat diketahui kekurangannya untuk dapat diberitahu bagian-bagian yang perlu diperbaiki. Kegiatan supervisi biasa dilakukan oleh kepala sekolah maupun pengawas (Keswara, 2013).

\section{PEMBAHASAN}

Adapun solusi yang dapat diberikan dari permasalahan di atas antara lain dengan mengubah sistem-sistem sosial yang berkaitan dengan sistem pendidikan. Pemerintah harus peka terhadap kondisi pendidikan di setiap daerah dan dapat mengambil langkah yang pasti untuk memperbaiki kualitas sesuai dengan kondisi daerah masing-masing.

Tidak hanya pemerintah, tetapi masyarakat juga harus bahu-membahu bersama pemerintah untuk dapat meningkatkan kesadaran bahwa pendidikan itu penting dan dapat selalu mengawasi kegiatan pendidikan di Indonesia. Perkembangan dunia di era globalisasi ini memang banyak menuntut perubahan kesistem pendidikan nasional yang lebih baik serta mampu bersaing secara sehat dalam segala bidang. Dengan meningkatnya kualitas pendidikan berarti sumber daya manusia yang terlahir akan semakin baik mutunya dan akan mampu membawa bangsa ini bersaing secara sehat dalam segala bidang di dunia internasional.

Pembinaan atas hasil supervisi tersebut bisa berupa bimbingan atau tuntunan ke arah perbaikan situasi pendidikan pada umumnya dan peningkatan mutu mengajar dan belajar pada khususnya. Namun ternyata dari berbagai hasil penelitian, pengamatan dan pengalaman, supervisi pendidikan belum mencapai tujuan tersebut.

Pelaksanaan supervisi saat ini tidak maksimal, kehilangan ruhnya. Jarang dilakukan inspeksi secara mendadak, apalagi diam-diam. Yang lazim, sudah ada pemberitahuan terlebih dahulu, meski satu hari sebelumnya

Dicontohkan, pelaksanaan supervisi yang baik telah dilakukan oleh SMP Negeri 4 Pakem, Sleman. Dengan pengawasan oleh kepala sekolah secara diam-diam, intens, berkomunikasi baik dengan Pengawas, menjaga hubungan baik dengan guru dan murid serta melakukan pembinaan dan pendampingan, dapat mengubah sekolah yang biasa menjadi sekolah luar biasa dengan berbagai prestasi, termasuk UN tertinggi di DIY.

Perkembangan supervisi pendidikan berkembang seiring dengan perkembangan ilmu pengetahuan, teknologi, serta sosial ekonomi dan budaya masyarakat. Supervisi bergerak dari berbentuk inspeksi dimana otoritas lebih didominasi oleh supervisor, berkembang dalam bentuk kolaborasi antara supervisor dan guru bersama berinisiatif dan bertanggungjawab 
dalam meningkatkan kualitas pembelajaran, serta menumbuhkan budaya belajar pada guru untuk selalu meningkatkan kompetensinya (Sabandi, 2013).

\section{KESIMPULAN DAN SARAN}

Berdasarkan pemaparan di atas, maka dapat diambil kesimpulan bahwa pendidikan di Indonesia seharusnya bisa berkembang dengan baik jika pemerintah dan masyarakat bisa bekerja sama dalam hal memperbaiki kualitas pendidikan dan sama-sama mencari solusi agar permasalahan dalam pendidikan bisa cepat teratasi.

\section{REFERENSI}

Ahmad Sabandi. 2013. Supervisi Pendidikan Untuk Pengembangan Profesionalitas Guru Berkeanjutan. Ilmu Pendidikan. 13(2): 3

Harususilo, Yohanes Enggar (2019, 20 Februari). 3 Soal Utama Pemberdayaan Pendidikan di Indonesia. Dikutip 14 April 2019 dari edukasi.kompas.com: https://edukasi.kompas.com/read/2019/02/20/07300091/3-soal-utama-pemberdayaanpendidikan-di-indonesia

Keswara, Ratih (2013, 12 September). Supervisi Pendidikan Belum Sesuai Harapan. Dikutip 14 April 2019 dari SINDONEWS.com: https://nasional.sindonews.com/read/782345/15/supervisi-pendidikan-belum-sesuaiharapan-1378980625

Kusumawardhani, Satya Adhi (2018, 14 Desember). Permasalahan Pendidikan di Indonesia. Dikutip 14 April 2019 dari Kantor Berita RMOL Jateng : http://www.rmoljateng.com/read/2018/12/14/15004/Permasalahan-Pendidikan-diIndonesia-

Nadlir, Moh (2018, 2 Mei). Komnas HAM Catat 4 Kondisi Darurat Pendidikan. Dikutip 14 April 2019 dari Kompas.com: https://nasional.kompas.com/read/2018/05/02/12581141/komnas-ham-catat-4-kondisidarurat-pendidikan-indonesia?page $=$ all 